\title{
PRÁTICAS MONOCULTORAS E TENSÕES SÓCIOTERRITORIAIS NO DISTRITO DE MIRAPORANGA - UBERLÂNDIA - MG
}

\author{
MONOCULTORIC PRACTICES AND SOCIO-TERRITORIAL TENSIONS IN THE MIRAPORANGA DISTRICT - \\ UBERLÂNDIA - MG
}

\author{
Nathália Ohana Ferreira Santos', Rosselvelt Jóse Santos ${ }^{1}$ \\ 1 Universidade Federal de Uberlândia (UFS), Uberlândia, MG, Brasil
}

\author{
Correspondência para: Nathália Ohana Ferreira Santos (nathaliaohana16@gmail.com) \\ doi: 10.12957/geouerj.2019.28744 \\ Recebido em: 09 mai. 2017 | Aceito em: 16 ago. 2019
}

\section{RESUMO}

No município de Uberlândia-MG, localizado na mesorregião do Triângulo Mineiro, os capitais investidos na agroindústria se reproduzem de forma intensa e acelerada. A partir do ano de 2008, mesmo o município não abrigando em seu território usinas processadoras de álcool e açúcar, as extensas lavouras de cana passaram a redefinir as paisagens rurais no distrito de Miraporanga. O cultivo dessas lavouras afetam as relações sociais dos antigos produtores rurais do lugarejo, introduzindo novas dinâmicas sócioterritoriais. Na divisa com o referido distrito, no município de Uberaba-MG encontra-se instalada uma planta de usina sucroenergética/sucroalcooleira. Para suprir as suas necessidades de matéria prima, áreas do referido distrito foram sendo capturadas para abrigar os enormes canaviais, compelindo os camponeses a conviver com essa nova dinâmica a qual afeta seus vínculos com o lugar e, até mesmo, seu modo de vida. No lugar, as tensões vão sendo fabricadas pelo próprio otimismo do capital. Assim, este trabalho aborda as tensões e reações dos sujeitos envolvidos.

Palavras-chave: Setor sucroenergético/sucroalcooleiro; Lugar; Tensões; Distrito de Miraporanga; Uberlândia (MG).

\begin{abstract}
At Uberlândia-MG's municipality, localized at Triângulo Mineiro's region, agribusiness is reproducing itself at an intense and accelerated rate. Since 2008, even though the municipality doesn't have sugarcane processing mills in operation at its territory, the existence of extensive sugarcane tillages are affecting the old rural producers of Miraporanga's district. Those subjects are compelled to live with this new dynamic which interferes their productions at the rural space and, even, their way of life. At Uberaba-MG's municipality, which covets limits with the referenced district, two sugarcane processingmill plants were installed. As a consequence, at the district's whereabouts it's possible to find extensive sugarcane tillages and orange orchards. So, at the district lands, landscapes of agribusinessare implemented. Along with these transformations, the rural space of the district is faced with a migratory process. These workers come from, especially, the Northwest and North region of the country and from some places of Minas Gerais' state. They come to the district not only to sell their workforce, but to realize life projects. In those circumstances, strangeness is fabricated at a place transposed by tensions that are derived by the capital's own optimism. This essay denotes the dynamics and relationships that are realized at the territory in a place called Miraporanga.
\end{abstract}

Keywords: Sugar and ethanol industry's expansion; Place; Tensions; Miraporanga's District; Uberlândia (MG).

\section{INTRODUÇÃO}

Historicamente, o Brasil constituiu-se em importante cultivador da cana-de-açúcar a qual foi introduzida em seu território no ano de 1532. A prática da monocultura da cana por expressivos períodos gerou 
dependência econômica, concentração de terras e riqueza, contribuindo para enormes disparidades sócioespaciais.

De acordo com a União das Indústrias da Cana-de-açúcar (UNICA, 2015), existem 371 unidades processadoras em atividade no país. Em concordância com o portal, tal condição faz com que o país receba o título de maior produtor mundial de cana, com aproximadamente 630 milhões de toneladas processadas nas safras de 2014/2015; com estimativa para o ano de 2016/2017 de 655 milhões de toneladas. Além disso, o setor gera mais de 900 mil empregos diretos e 70 mil produtores rurais independentes de cana-de-açúcar.

Essa condição é sustentada pelo fato de a cana-de-açúcar ser uma das principais fontes de energia renovável do país, correspondendo por mais de $15 \%$ da matriz energética nacional. 0 país encontra-se acima da média mundial no que confere ao uso de energias limpas e renováveis. O bagaço da cana-deaçúcar, devido ao seu alto teor de fibras, desde o período da revolução industrial, vêm sendo empregado para a produção de vapor e energia elétrica. Na usina Uberaba, a qual estendeu as suas lavouras para Miraporanga, o bagaço é utilizado na geração de energia para consumo na própria usina, sendo o excedente comercializado com a Companhia de Energia Elétrica de Minas Gerais, (CEMIG).

Considerando-se a quantidade de cana processada no Brasil, além de atender as necessidades energéticas das usinas, desde os anos de 1980, o bagaço da cana tem possibilitado a geração de excedentes de energia elétrica que, posteriormente, são fornecidas ao sistema elétrico nacional. Somente no ano de 2011, a produção da bioeletricidade para o sistema energético brasileiro foi capaz de atender 20 milhões de pessoas. Ainda de acordo com a União das Indústrias da Cana-de-açúcar (UNICA, 2012), a bioeletricidade fornecida para a rede elétrica, por ser complementar a fonte de energia hídrica, proporcionou uma economia de 5\% da água dos reservatórios das Regiões Sudeste e Centro-Oeste no período seco daquele ano. 
Em decorrência destas práticas compreendem-se as razões pelas quais o setor sucroalcooleiro/sucroenergético caracterize a produção dessa energia como associada ao rótulo de "verde" e sustentável.

No que confere ao açúcar, o país é o maior produtor e exportador do mundo, equivalendo a $20 \%$ da produção global e 40\% da exportação mundial.

O Brasil comparece no mercado mundial como o segundo maior produtor global de Etanol, um dos subprodutos da cana, ficando atrás apenas dos Estados Unidos da América. Esse combustível, em tese, é uma das melhores alternativas para reduzir a emissão de gases que causam o efeito estufa, pois, a sua queima como combustível reduz em 70\% a emissão de CO2 na atmosfera quando comparado a gasolina.

Não obstante, o Etanol ganhou destaque no cenário mundial a partir do momento em que a questão ambiental e, sobretudo, a problemática do aquecimento global ocuparam centralidade nas discussões relacionadas ao meio ambiente e sua preservação. Para que fosse possível efetivar a utilização desse combustível, o país investiu durante anos em pesquisas e tecnologias para produzir Etanol de forma eficaz (FREITAS, 2015).

Porém, para alcançar essa posição foi necessário aumentar expressivamente a quantidade de usinas processadoras e instalar as lavouras de cana em terras férteis e em áreas cuja infraestrutura permitisse explorar a fluidez do espaço. Durante a safra do ano de 2015/2016 a área colhida de cana-de-açúcar unicamente destinada ao setor sucroalcooleiro/sucroenergético atingiu o quantitativo de 8.654,2 mil hectares, sendo que 10,1\% encontravam-se no Estado de Minas Gerais (Companhia Nacional de Abastecimento - CONAB, 2016).

No ano de 2016, a região Centro-Sul, divisão geográfica que inclui o Sul, Sudeste e Centro-Oeste do território brasileiro, atingiram 90\% do volume total produzido de cana. Os outros 10\% cabem aos Estados da região Norte-Nordeste, de acordo com o Portal ÚNICA (2015). No entanto, esta realidade foi sendo processada diferentemente ao longo da história do país. A região Nordeste, historicamente, foi 
à maior produtora da cultura da cana-de-açúcar desde meados do século VXI, perdurando até o século XIX. Durante esse período, o açúcar era exportado sem concorrências, porém, com a utilização do açúcar derivado da beterraba e leis protecionistas estabelecidas na Europa, o país enfrentou uma dura crise concorrencial ainda no século XIX. Após a referida crise, a industrialização da cana se efetivou na região Centro-Sul.

Dentre as idas e vindas da cultura da cana-de-açúcar e as transformações que são derivadas/fabricadas no bojo desse processo e que marcam a história do país, encontra-se o município de Uberlândia-MG emerso no Cerrado Mineiro, e localizado na Mesorregião do Triângulo Mineiro.

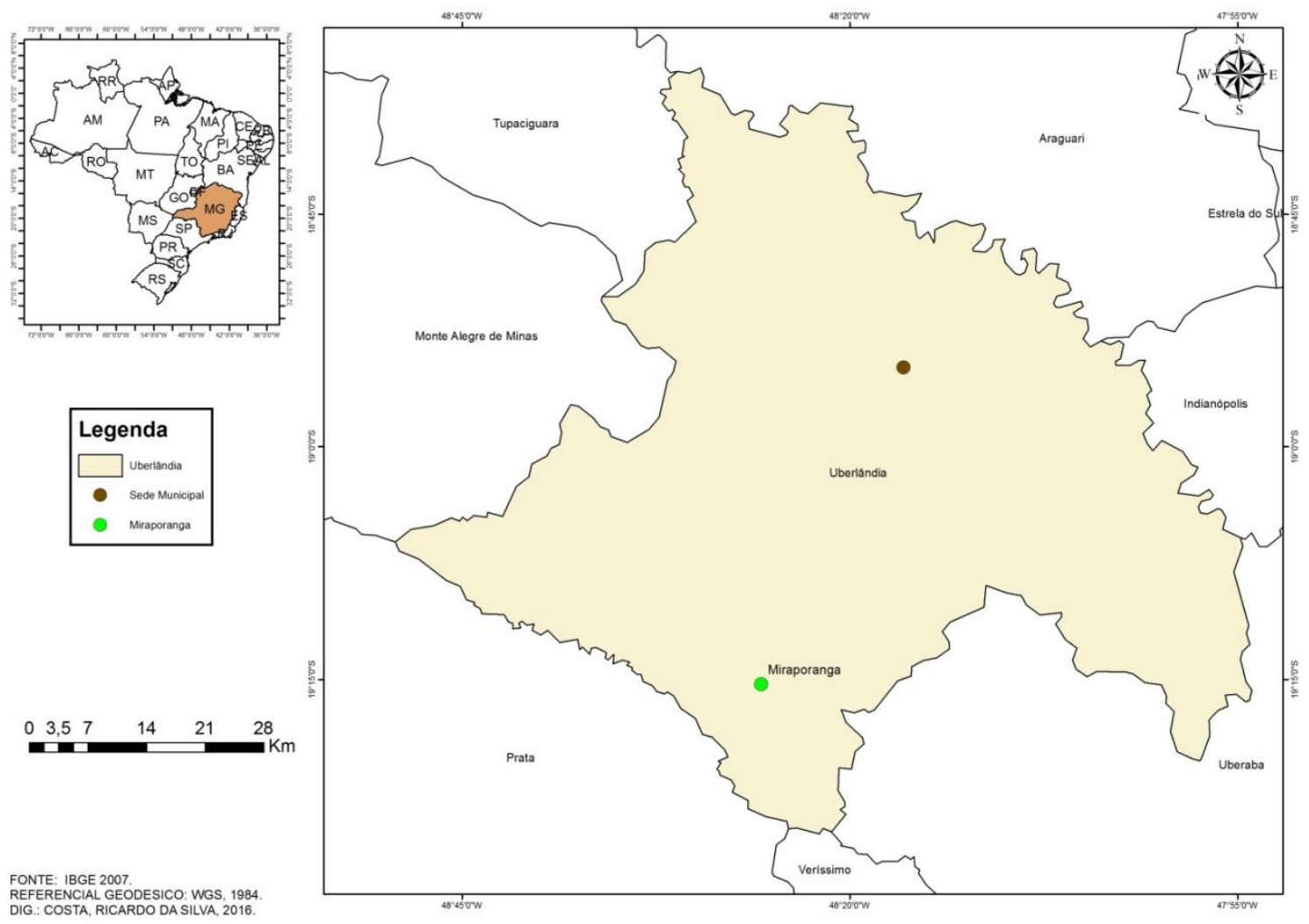

Figura 1. Localização do município de Uberlândia (MG). Fonte: IBGE, 2007.

A extensão territorial do município uberlandense é de 4.115,206 km², onde, $3.896 \mathrm{~km}^{2}$ correspondem ao espaço rural e, 219,09 km² estão envolvidos para a área urbana. 0 município possui quatro distritos, sendo eles Miraporanga, Tapuirama, Cruzeiro dos Peixotos e Martinésia, os quais distam em média 25 km da sede. Os distritos de Martinésia e Cruzeiro dos Peixotos estão localizados em um relevo mais 
acidentado e próximo ao Vale do Rio Araguari, como consequência, o agronegócio se manifesta na criação de gado, aves e suínos. No que diz respeito à Tapuirama e Miraporanga, o relevo é plano, composto por chapadas, possibilitando uma maior mecanização, fomentado o agronegócio em extensas lavouras de soja, milho, laranja e mais recentemente (meados da segunda década do século XXI), a canade-açúcar.

Ademais, em Uberlândia, o agronegócio é tido como um dos mais desenvolvidos do interior brasileiro pelo fato de várias estruturas urbanas contribuírem para a remuneração dos capitais investidos no setor. Além disso, historicamente, a região é considerada grande produtora de leite e seus derivados. O título de bacia leiteira é resultante de uma produção que envolve a lógica camponesa. Nestas propriedades pode ser encontrado, em distintas proporções o emprego de novas tecnologias, quanto a utilização de técnicas mais antigas e/ou tradicionais.

Com relação aos cultivos de soja e milho, as principais empresas que atuam no município são BUNGE, ADM, Algar Agro e Cargill, porém algumas destas não trabalham apenas com grãos, mas também com outros cultivos agroindústrias, como a laranja, conforme observado por Freitas (2015). A plantação dessas culturas nas terras do Cerrado Mineiro se deu na década de 1970, a partir de incentivos governamentais que visavam o melhor uso e aproveitamento dessas terras, incorporando, em larga escala, inovações tecnológicas, "correção" dos solos do Cerrado, assistência técnica e programas oficiais de créditos subsidiados. O período conhecido por "Revolução Verde" foi propulsor para a efetivação das monoculturas de grãos.

O cultivo da soja e do milho em grandes áreas na mesorregião do Triângulo Mineiro foram gerenciadas pelo JICA-PRODECER, (Japan International Cooperation Agency / Programa de Cooperação para Desenvolvimento do Cerrado). O programa reuniu naquela mesorregião do Cerrado Mineiro capital japonês e brasileiro (SANTOS, 2008). A partir dos anos de 1980 promoveu o enraizamento de grandes lavouras e que funcionaram como símbolos das conquistas científicas e tecnológicas sobre os solos do Cerrado, tidos, principalmente pelos produtores tradicionais, como inapropriados para a agricultura. 
Contudo, com a derrubada do mito do Cerrado improdutivo, a monocultura praticada em terras planas, a partir de políticas públicas foi remunerando os capitais investidos, proporcionando uma nova dinâmica sócioespacial. Mudanças no perfil da produção agrícola foram efetivadas por migrantes gaúchos, os quais na condição de despossuídos de propriedade no Sul do país aceitaram as imposições do Programa JICAPRODECER, e em terras do Cerrado Mineiro foram realizando seus projetos de vida, fixando nas paisagens as grandes lavouras de grãos (SANTOS, 2008).

A comprovação que o Cerrado poderia produzir grãos em larga escala, inclusive para atender ao mercado externo foi fundamental para que houvesse, no Triângulo Mineiro, um processo de reocupação, revalorização e reordenamento das atividades agropecuárias, bem como o surgimento de novas gentes e suas racionalidades. Nas áreas de chapadas, além das grandes lavouras vão surgir os novos moradores, os maquinários, as edificações e as instituições para dar fluidez aos novos negócios. Consequentemente, as áreas agricultáveis do município de Uberlândia foram incluídas.

\section{PROCEDIMENTOS METODOLÓGICOS}

Para alcançarmos o objetivo proposto no estudo foi realizado no período de dois anos levantamento de material bibliográfico no acervo disponível na biblioteca e na internet. Conseguimos ter acesso a revistas, livros, artigos e sites especializados. A leitura e fichamento desse material forneceu amparo teórico para a temática envolvendo a expansão da cultura da cana-de-açúcar sob as terras do Cerrado no município de Uberlândia e colaborou para a compreensão de como os desdobramentos deste processo promoveram modificações no lugar, afetando os sujeitos que compõem essa realidade.

As categorias de análise geográficas foram revisadas. Lugar, território e paisagem foram estudadas, ampliando assim os nossos entendimentos sobre o modo de vida das pessoas e as tensões decorrentes do processo de instalação das grandes lavouras.

Quantitativamente as manifestações do agronegócio foram sendo estudadas, considerando-se os dados disponibilizados na plataforma SIDRA, de domínio do Instituto Brasileiro de Geografia e Estatística 
IBGE. Os objetivos relacionados ao levantamento de dados consistiram na estruturação e análise espacial e temporal do cultivo da cana. Ainda na perspectiva do quantitativo, o Portal ÚNICA foi consultado, assim como o CANASAT e a CONAB, sites especializados na cultura da cana-de-açúcar.

Com relação a área de estudo foram realizados vários trabalhos de campo. Conforme discutido por Matos e Pessôa (2009) sobre a pesquisa qualitativa, os procedimentos mais utilizados são: entrevista, observação, observação participante, análise do discurso, pesquisa-ação, história oral e estudo de caso. Por isso, cabe ao pesquisador estabelecer a técnica ou as técnicas que se adequem mais aos seus objetivos, de modo que consiga alcançar resultados, sustentando o desenvolvimento do estudo.

Portanto, no distrito Miraporanga dialogamos por vários dias com antigos moradores e produtores rurais a partir de entrevistas semiestruturadas e também por meio da história oral, onde esses falaram de forma livre e espontânea, possibilitando o detalhamento da vida das pessoas envolvidas nessa dinâmica.

Com a efetivação desses procedimentos estabelecemos análises das tensões vivenciadas pelas pessoas que se encontram no lugar reocupado pelo agronegócio. Com o emprego de entrevistas semiestruturadas iniciamos também diálogos com os sujeitos do/no lugar e observação da paisagem. Além disso, durante a realização dos trabalhos de campo, foram estabelecidos procedimentos de comparações dos conteúdos das falas das pessoas, promovendo entendimentos contundentes a respeito desse processo que movimenta e transforma a vida no lugar Miraporanga.

Assim, inicialmente apresentamos o contexto no qual o distrito de Miraporanga está inserido. Esse é composto por uma pequena comunidade que se mostra capaz de reivindicar seus direitos junto ao poder público e conquistar os serviços que avaliam necessários para atender as demandas da sua realidade, como o transporte público que o conecta ao distrito sede do município de Uberlândia, além de saúde, educação, segurança pública, saneamento básico, dentre outros.

Contudo, embora não seja o nosso objetivo tratar diretamente dos impactos sociais e infraestruturais, torna-se necessário destacar que as atividades associadas ao monocultivo canavieiro, impõe o 
deslocamento de importantes contingentes de trabalhadores, cuja presença acaba demandando novas habitações e sobrecarregando aqueles serviços públicos que a comunidade conquistou.

$\mathrm{Na}$ seção seguinte, são expostas as estratégias inventadas e efetivadas pelos camponeses para enfrentarem o avanço da cana-de-açúcar sobre o seu território. Esses, em comunidade, criam arranjos sócioprodutivos e culturais para promoverem a sua existência e assim resistirem às tensões decorrentes do setor sucroalcooleiro/sucroenergético. Em certa medida desenvolvem, dia após dia, o seu modo de vida e jeitos para permanecerem gerando renda e trabalho no/do lugar. Ao final, apresentamos nossas considerações a problemática aqui abordada.

\section{RESULTADOS}

\section{MIRAPORANGA: TRANSFORMAÇÕES NO LUGAR}

No século XXI, em Uberlândia, nas terras de chapada passou-se a intensificar o cultivo de grãos utilizando-se a irrigação. Neste mesmo século os investimentos aplicados no setor sucroenergético/sucroalcooleiro na região de Uberlândia, promoveram o aumento do cultivo de cana-deaçúcar. Esta cultura comparece no município para atender as demandas da agroindústria instalada fora dos seus domínios territoriais, promovendo profundas transformações no modo de vida das pessoas que vivem no distrito de Miraporanga.

Atualmente, (2017) Miraporanga conta com população total de 6.948 habitantes. Em comparação com os demais distritos de Uberlândia, trata-se de um pequeno povoado rural. As moradias do vilarejo abrigam 240 pessoas, sendo que 6.708 habitantes vivem no espaço rural.

O principal acesso ao distrito é a rodovia MGC-455, que liga Uberlândia ao município de Campo Florido. Partindo-se da sede municipal, nos trabalhos de campo, chegávamos ao vilarejo, após percorrermos 40 km. Os municípios de Uberaba e Indianópolis fazem limite com o distrito. Seu relevo é plano, predominantemente de chapada, onde é possível maior mecanização das lavouras de soja, sorgo, milho, 
laranja e recentemente da cana-de-açúcar, cultura que inaugura um processo acelerado de reocupação do espaço distrital e que se desdobra em várias dinâmicas sócioprodutivas.

Em 2013, Miraporanga, após processos de reinvindicações dos seus moradores, passou a contar com linha de transporte coletivo urbano, conforme dados disponibilizados pela Secretaria Municipal de Planejamento Urbano da Prefeitura Municipal de Uberlândia (2016).

Na Vila distrital encontram-se uma Base Comunitária da Policia Militar (PM), a Escola Municipal Domingas Camin, o Posto de Saúde Miraporanga e uma Mercearia ligada a um restaurante. Como relíquia religiosa do lugar, tem-se a Igreja de Nossa Senhora do Rosário.

Apesar de próxima ao distrito, aproximadamente $30 \mathrm{~km}$, a usina Uberaba está sediada no município de Uberaba-MG. Conquanto, as produções de cana avançam significativamente sobre o território uberlandense, consolidando-se tensões na área limítrofe ou, de fronteira, o distrito vai recebendo migrantes para trabalhar na usina, estrangulando a capacidade de seus serviços públicos, principalmente escolar, saúde e de segurança pública.

A usina ao se instalar nas proximidades do distrito acaba instituindo outras lógicas sócioprodutivas. No lugar surgem rearranjos produtivos e infraestruturais de forma a causar conflitos e tensões ou mesmo intensificá-los, conforme considerado por Freitas (2015).

Destarte, diversas lógicas sociais são fabricadas/derivadas no interior dos processos de cultivo das lavouras de cana-de-açúcar. Analisar as singularidades dessas conexões/nexos podem nos ajudar a compreender as distintas características que compõem os lugares vividos, assim como suas humanidades.

No lugar estudado evidencia-se que as culturas da soja, milho, sorgo, laranja e da cana-de-açúcar instauraram paisagens homogêneas, como podemos observar no mosaico (Figura 2). Nas duas primeiras imagens, à esquerda, lavoura de soja e a direita milho. Nas duas últimas imagens, à esquerda, cana-deaçúcar e a direita, sorgo. 


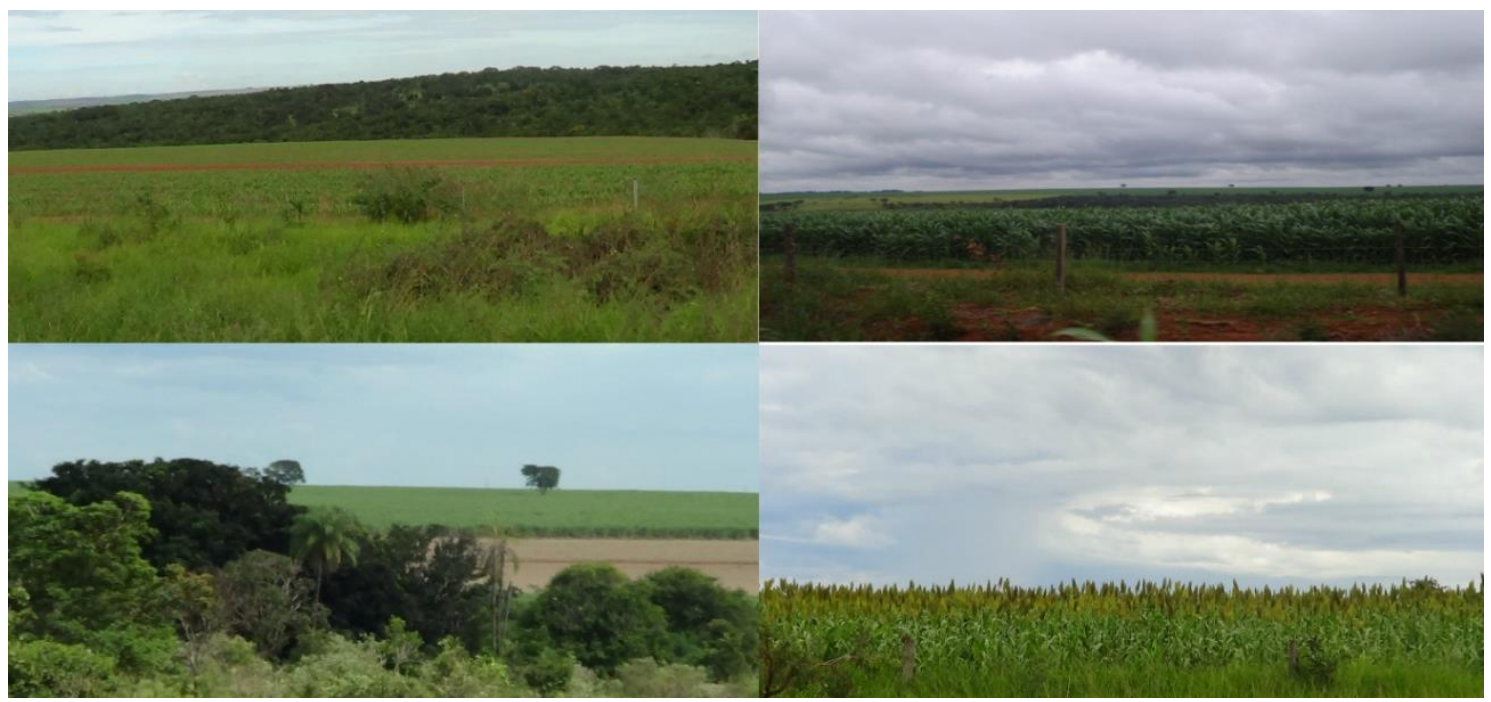

Figura 2. Paisagens Homogêneas no Distrito de Miraporanga, Uberlândia-MG.. Fonte: FREITAS, J. S, 2014.

Ao analisarmos os dados referentes à expansão da cana-de-açúcar em áreas pertencentes ao município de Uberlândia, entre os anos de 2004 e $2014^{1}$, constatamos situações um tanto quanto inconstantes. Entre os anos de 2004 e 2012 a expansão das lavouras de cana-de-açúcar ocorreu de forma equilibrada. Somente a partir de 2013 que ocorre um significativo crescimento.

Segundo dados do Instituto Brasileiro de Geografia e Estatística - IBGE (2016), Gráfico 01, no ano de 2004, no município de Uberlândia, as lavouras de cana-de-açúcar somavam 50 hectares. Dez anos depois (2014) a expansão dessas lavouras apresentou um aumento de $21.160 \%$ correspondendo a um acréscimo de 11 mil hectares plantados.

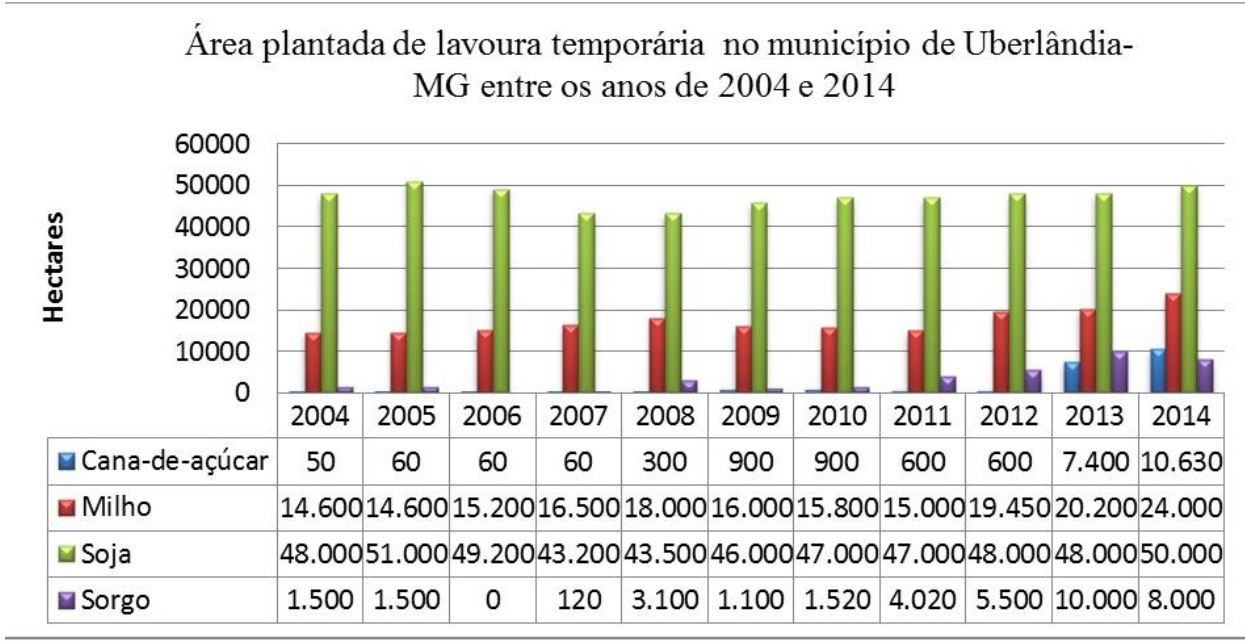

Figura 3. Área plantada de lavoura temporária no município de Uberlândia - MG entre os anos de 2004 e 2014 . Fonte: IBGE/SIDRA, 2016.

\footnotetext{
${ }^{1}$ Últimos dados disponibilizados para consulta na plataforma SIDRA do IBGE.
} 
Apesar do expressivo crescimento das lavouras de cana, nos dez anos analisados é perceptível o crescimento do cultivo de grãos. De acordo com Freitas e Santos (2013),

\footnotetext{
Este fator leva também ao fortalecimento da criação de aves, suínos e bovinos. O agronegócio ligado as carnes utiliza os grãos como alimento para os animais. Vemos então, uma espécie de cooperação entre os criadouros e o processamento de grãos, tendo interesse econômico e em parte político, pois, assim, se fortalecem no campo tornando dificultoso para que outras culturas, principalmente, a cana avancem com tanta força como em outros municípios. (FEITAS, SANTOS 2013, p. 14).
}

Compreende-se que a cultura de grãos se encontra estruturada no município e pode ser entendida como uma das responsáveis por "barrar" a expansão das lavouras de cana-de-açúcar sobre outras partes do território uberlandense.

Para melhor visualizarmos o aumento do cultivo da cana, na figura 4, está posto um mosaico que demonstra a extensão das lavouras da cana-de-açúcar a partir de imagens de satélites sob o território uberlandense.
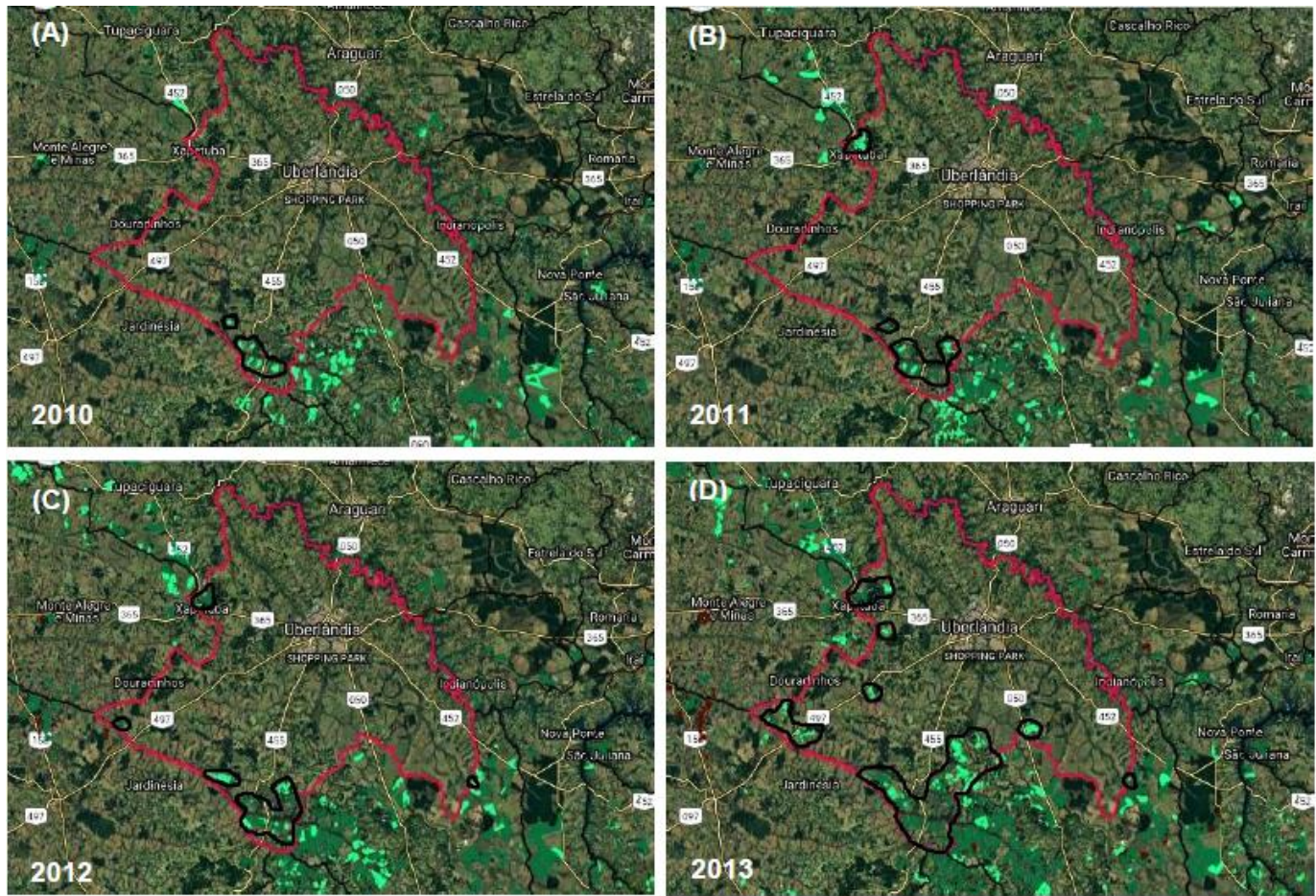

Legenda
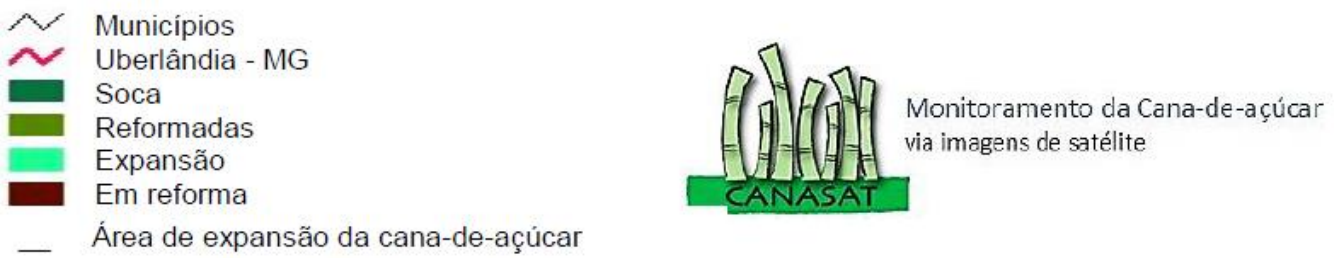

Figura 4: Área da expansão da cana-de-açúcar entre 2010 e 2013Fonte: CANASAT; INPE. 
Utilizamos as imagens mais recentes que estão disponíveis para consulta na plataforma CANASAT. Em vermelho está delimitado o município de Uberlândia e, em preto a área de expansão das lavouras de cana-de-açúcar (tons de verde) entre os anos de 2010 e 2013. Quando analisamos as informações contidas na figura 4, observa-se que a área agricultável do município, próxima a usina Uberaba, vem sendo rapidamente reocupada pelas lavouras de cana.

Por conseguinte, é preciso considerar que, novas formas de produção no meio rural são adotadas devido à reprodução dos capitais investidos no setor sucroalcooleiro/sucroenergético, resultando em um (re) ordenamento sócioterritorial. Além disso, tais investimentos reestruturam as relações sociais e culturais estabelecidas pelos antigos produtores, pois sofrem influências dessas novas dinâmicas sócioprodutivas (INÁCIO; SANTOS, 2011).

Neste contexto, compreende-se que as transformações ocasionadas pelas ações do setor sucroalcooleiro/sucroenergético ao homogeneizar a paisagem também contribuem para a transformação do espaço e os modos de vida daqueles que vivem no lugar.

Nesta conjuntura, tornam-se necessário apresentar as práticas sociais dos camponeses e suas estratégias para que possamos compreender como eles se comportam no lugar.

\section{Estratégias Camponesas}

Consideramos camponeses aqueles sujeitos que dedicam suas vidas às produções no campo e a sua família, de modo a garantir a satisfação de suas necessidades sociais. Dado que, o campo não é apenas um espaço de produção, mas sim, um espaço com um tecido social que possui identidade, história (GULARTE, 2013).

Em Miraporanga, nos últimos anos, os camponeses, estão vivendo encurralados pelas lavouras de cana e interesses do setor sucroalcooleiro/sucroenergético. Porém, essa situação não eliminou os camponeses do lugar Miraporanga. 
Para as pessoas que vivem no lugar, o Vilarejo era "um lugar tranquilo, bom para se viver" ${ }^{2}$, configurando-se como um espaço em que as pessoas se conheciam, se visitavam, propiciando um modo de vida comunitário.

Apesar disso, o distrito vivenciou profundas mutações sócioterritoriais, principalmente a partir da instalação da usina Uberaba. Como consequências deste processo foram sendo estabelecidos nesse território vários estranhamentos, promovendo transição de valores humanos e rompimentos de vínculos com o lugar. Essa situação pode ser percebida na seguinte fala:

\footnotetext{
Aqui a gente tinha tranquilidade, o povo se visitava, sabia quem era [...] A gente tinha como deixa a casa aberta, sem tranca [...] era uma beleza [...] hoje tá tudo dimudado, não sabe quem aquela pessoa, de onde venho, qual a intenção dela [...]. Então eu digo que o povo foi perdendo Miraporanga. ${ }^{3}$
}

Contudo, é necessário considerar que há um processo de reocupação que se agudiza a partir dos anos de 1980. Trata-se de um período anterior ao cultivo da cana, da usina e da migração de trabalhadores temporários. Antes do cultivo da cana, as áreas destinadas a pecuária foram reocupadas pelas culturas de soja, sorgo, milho e laranja. Na fala do pesquisado, a memória deste processo de reocupação comparece como sendo a dos eventos mais recentes. É necessário lembrar que a monocultura já estava presente no distrito antes da cana.

Certamente o cultivo da cana impactou a vida no distrito de forma rápida e acelerada. Trata-se de um fenômeno que afeta uma realidade que se manifesta na paisagem do distrito. Diante disso, o conteúdo da próxima entrevista indica que as tensões são fabricadas no lugar e afetam o modo de vida dos sujeitos que estão inseridos nesse processo.

\footnotetext{
A nossa escola tá cheio de criança que não é daqui. Elas chegam hoje, amanhã já vão pra outro lugar. Você vai no posto não tem como você ser atendido, tem fila, e dai não tem atendimento de antes, é tudo corrido, é tudo de um jeito que a pessoa não te olha, não cumprimenta, fica uma coisa muito estranha. ${ }^{4}$
}

\footnotetext{
${ }^{2}$ Fonte: Diálogos com camponeses de Miraporanga- trabalho de campo setembro de 2014 - acervos - LAGECULT.

${ }^{3}$ Fonte: Diálogos com camponeses de Miraporanga- trabalho de campo setembro de 2014 - acervos - LAGECULT.

${ }^{4}$ Fonte: Diálogos com camponeses de Miraporanga- trabalho de campo setembro de 2014 - acervos - LAGECULT.
} 
Diante das singularidades que acompanham a manifestação do agronegócio nas terras do distrito, encontra-se um sujeito social que dia após dia é submetido às diversas imposições que são estabelecidas num espaço em que a referência que se tinha antes das grandes lavouras de cana era de uma vida pautada em valores humanos, estabelecidos e nutridos a partir da catolicismo e baseados em relações comunitárias. Na narrativa a seguir comparece uma comparação de situações socioespaciais que remetem ao processo de reocupação do território, evocando memórias e práticas sociais camponesas.

Antes da cana, não tinha asfalto, não tinha tanta gente diferente andando por ai procurando trabalho na usina. O povo era mais unido [...]. Nas missa era sempre cheio, assim um povo juntado na Igreja. Hoje tá difícil prá gente que é pequeno contar com um vizinho, um peão que vai lá e te ajude no serviço de ordenha daquele jeitinho, naquele dia de precisão e naquele valor. Hoje a usina paga melhor e a gente não consegue acompanha. Então aqui tinha mais opcão de companheiro prá faze o serviço. ${ }^{5}$

Esse sujeito que sente o atual momento a partir da ausência da proximidade de vizinhos e também de trabalhadores aptos a desempenhar as atividades cíclicas e ou temporárias, ligadas a pecuária leiteira, indica que a sua condição de camponês encontra-se seriamente ameaçada pelo agronegócio. Sem vizinhos os encontros comunitários ficam prejudicados, bem como as relações sociais que lhes possibilitavam diversas trocas. Portanto, o esvaziamento da comunidade rural é interpretado como uma importante ameaça a sua existência no lugar, pois afeta as suas relações comunitárias e a sua principal fonte de renda. Assim, o camponês compreende o contexto, manifestado que:

O leite é o salário do pequeno, assim, do roceiro [...]. Se tá difícil com o leite, pior fica sem ele [...]. Não dá pra fica sem um leitinho[...]. Aqui na roça leite paga conta. Depois, a gente sabe mesmo mexe com leite [...]. Sem leite muita gente abandonou a roça e foi pra cidade. Dai a gente ficou, mais sente falta dos vizinhos [...]. ${ }^{6}$

Seus conhecimentos, habilidades estão fortemente relacionados a pecuária leiteira. Seus laços sociais propiciavam realizações de troca de serviços, pois a partir das vizinhanças, relações sociais eram estreitadas. Como consequência, impasses gerados pela falta de mão de obra, são interpretados como sem solução. Além disso, o preço dos arrendamentos resultantes da dinâmica do setor sucroalcooleiro/sucroenergético apresenta-se como empecilhos para que aquele camponês consiga arrendar áreas e efetivar saídas para alimentar os seus rebanhos, sobretudo em períodos de estiagem.

\footnotetext{
${ }^{5}$ Fonte: Diálogos com camponeses de Miraporanga- trabalho de campo setembro de 2014 - acervos - LAGECULT.
}

${ }^{6}$ Fonte: Diálogos com camponeses de Miraporanga- trabalho de campo setembro de 2014 - acervos - LAGECULT. 


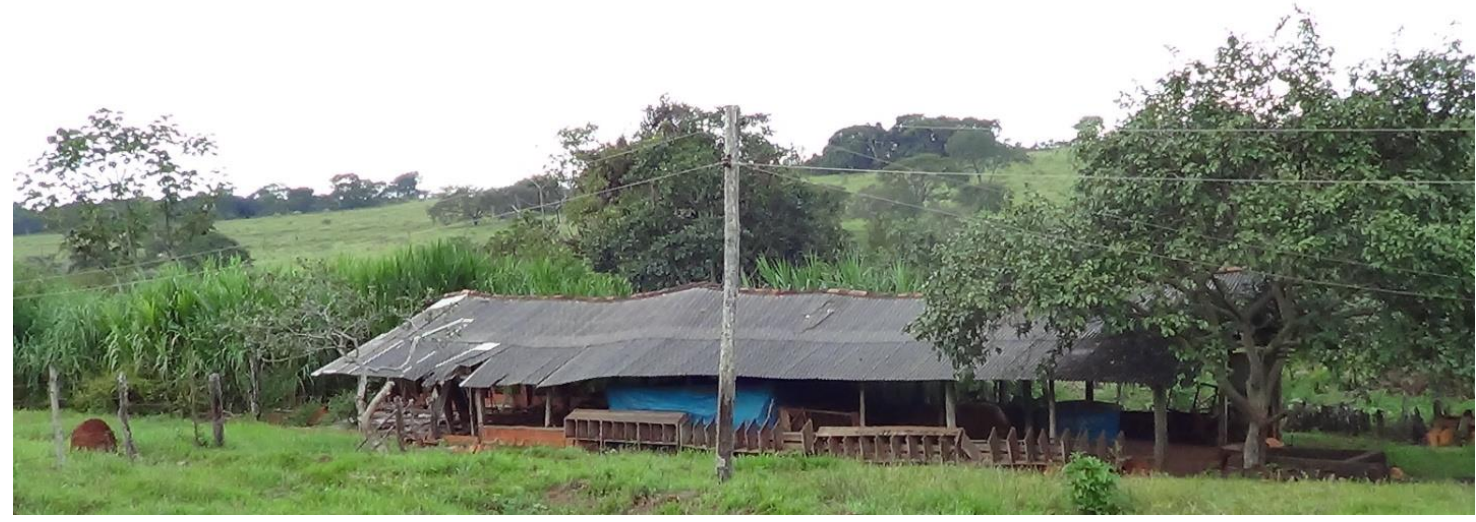

Figura 5. Cana em propriedade camponesa, distrito de Miraporanga, Uberlândia-MG.Fonte: FREITAS, J. S. 2014.

A paisagem presente na figura 5 indica que o cultivo da cana-de-açúcar compõe as paisagens das propriedades camponesas. Entretanto, trata-se de pequena plantação que, geralmente, no período seco é utilizado como volumoso a ser servido ao gado. Aquele canavial funciona como um estoque de alimento que misturado com ração, abastecerá os cochos das vacas para a obtenção do leite.

No que confere a utilização da tecnologia, o trator, triturador e o carretão são maquinários que funcionam como facilitadores do trabalho diário das famílias e tendem amenizar a carência de mão de obra. Outra medida adotada pelas famílias é a construção de silos de superfície envolvendo a comunidade, os quais funcionam como estoques de alimentos para nutrir o rebanho, permitindo certa estabilização da renda familiar. Essas estratégias apresentam-se como uma forma criativa de existir no lugar, permitindo-lhes alternativas para enfrentar as incertezas da vida e do próprio espaço.

\section{CONSIDERAÇÕES FINAIS}

Objetivou-se desenvolver uma abordagem geográfica do processo de reocupação do espaço rural do distrito de Miraporanga, o qual é permeado por interesses econômicos que se particularizam nas especificidades das tensões fabricadas pelo setor sucroalcooleiro/sucroenergético. Tratamos de analisar diferentes práticas sociais que colocam lado a lado o modo de vida camponês e os investimentos capitalistas vinculados ao setor sucroalcooleiro/sucroenergético. No lugar esse processo pelo lado da 
usina se manifesta intensificando práticas associadas às monoculturas, enquanto que do lado do camponês sobressaem a relações de mutualismo.

Especificamente, nos cultivos dos canaviais, usos de várias tecnologias vêm conseguindo impactar a pecuária leiteira, assim como, afetar os modos de vida dos camponeses.

Não obstante, as histórias de vida dos camponeses do lugar, obtidas a partir de diálogos livres durante os trabalhos de campo, são constituídas por múltiplas relações sociais e culturais e expressam vários significados e relevância para continuarem praticando a pecuária leiteira.

As relações sociais indicam uma articulação em rede, incluindo aqueles que saíram, mas nutrem alguma identidade com o lugar, estabelecendo novas sociabilidades camponesas. Embora ameaçada pelo valor do arrendamento, os que permanecem participam da vida comunitária. Apesar disso, é daquilo que restou da velha comunidade que eles se orientam para desenvolverem práticas produtivas que vão permitir a elaboração, por exemplo, de silos de superfície, sustentados por relações sociais fundamentadas na ajuda mútua. Nelas estão objetivadas a redução de custos e estratégias sócioculturais envolvendo a reciprocidade.

Nesta perspectiva, apesar do camponês vir perdendo partes de seus territórios para o cultivo da canade-açúcar, há reações. Elas vão além da produção da silagem para alimentação do gado no período seco, pois podem ser lidas a partir da execução de estratégias como o melhoramento do rebanho por meio da aquisição de sêmens ou de touros melhorados geneticamente; obtenção de máquinas e equipamentos voltados para a pequena propriedade; trocas de serviços e instrução técnica dos seus familiares. Esse comportamento pode estar indicando que o camponês, diante de situações de tensões, consegue se apresentar resiliente.

\section{AGRADECIMENTOS}


Agradecemos ao $\mathrm{CNPq}$ (Conselho Nacional de Desenvolvimento Científico e Tecnológico) pelo apoio e incentivo e aos moradores do distrito de Miraporanga, sem eles a pesquisa não seria possível de realização.

\section{REFERÊNCIAS}

CONAB - Companhia Nacional de Abastecimento. Acompanhamento da safra brasileira de cana-de-açúcar, 2013. Disponível em: http://www.conab.gov.br. Acesso em 13 jun. 2016.

FREITAS, J. S. Entre homens e culturas: fronteiras e limites na expansão da cana-de-açúcar nos distritos de Miraporanga e Tapuirama no Município de Uberlândia-MG. 2015. 92 f. Monografia (Graduação em Geografia) - Universidade Federal de Uberlândia, Uberlândia, 2015.

FREITAS, J. S. ; SANTOS, R. J. As tensões socioambientais da expansão das lavouras de cana-de-açúcar e o papel das tecnologias na produção camponesa - Município de Uberlândia. Horizonte Científico, Uberlândia, vol. 9, n 2, p. 1-23, Dez. 2015. Acesso em: http://www.seer.ufu.br/index.php/horizontecientifico/article/view/24300

FREITAS, J. S.; SANTOS, R. J. A presença do setor sucroalcooleiro e as tensões territoriais no espaço rural de UberlândiaMG. In: SIMPÓSIO NACIONAL DE GEOGRAFIA AGRÁRIA, Jornada das águas e comunidades tradicionais, VI. I. 2013, João Pessoa. Anais... João Pessoa: A questão agrária no século XXI: escalas, dinâmicas e conflitos territoriais, 2013. p 1 11. CD-rom.

GULARTE, E. B. A concepção de espaço rural e urbano nas políticas de desenvolvimento territorial do Governo Lula (20032010). In: SAQUET, Marcos (Org.). Estudos territoriais na ciência geográfica. São Paulo: Outras Expressões, 2013. p. 207-225.

INÁCIO, J. B.; SANTOS, R. J. A expansão da cana-de-açúcar nos territórios de produtores tradicionais do Triângulo Mineiro-MG. Revista Percurso-NEMO. Maringá, vol. 3, nº. 2, p. 167-195, $2^{\circ}$ sem. 2011.

MATOS, Patrícia Francisca de; PESSÔA, Vera. Lúcia. Salazar. Observação e entrevista: construção de dados para a pesquisa qualitativa em geografia agrária. In: RAMIRES, Julio C. de L.; PESSÔA, Vera L. S. (Org.). Geografia e pesquisa qualitativa: nas trilhas da investigação. 1aed.Uberlândia -MG: Assis Editora, 2009, p. 279-291.

Prefeitura Municipal de Uberlândia. Miraporanga: breve histórico. Disponível na internet: http://www.uberlandia.mg.gov.br/?pagina=Conteudo\&id=492. Acesso em: 13 jul. 2016.

SANTOS, R. J. Gaúchos e Mineiros do Cerrado: metamorfoses das diferentes temporalidades e lógicas sociais. $1^{\text {a }}$ ed. Uberlândia: EDUFU, 2008. 249p.

SOUZA, Z. J. Bioeletricidade: o que falta para esta alternativa energética deslanchar. 2012. Disponível na internet: http://www.unica.com.br/colunas/470156692036979688/ bioeletricidadeporcento3 Aoquefaltaparaestaalternativa/. Acesso em: 13 de julho de 2016 .

UNICA, Portal. Fotografia do setor sucroenergético no brasil. 2015. Disponível em: http://www.unica.com.br/. Acesso em: 13 de junho de 2016. 